\title{
Moderate Zinc Deficiency Influences Arterial Blood Pressure and Vascular Nitric Oxide Pathway in Growing Rats
}

\author{
ANALÍA L. TOMAT, ADRIANA R. WEISSTAUB, AGUSTÍN JAUREGUI, ADRIANA PIÑEIRO, \\ ANA M. BALASZCZUK, MARÍA A. COSTA, AND CRISTINA T. ARRANZ \\ Cátedra de Fisiología, [A.L.T., A.J., A.M.B., M.A.C., C.T.A.], Cátedra de Nutrición [A.R.W.], Cátedra de Toxicologiá \\ [A.P.], Facultad de Farmacia y Bioquímica, Universidad de Buenos Aires, Buenos Aires, Argentina
}

\begin{tabular}{|c|c|}
\hline \multicolumn{2}{|c|}{ ABSTRACT } \\
\hline $\begin{array}{l}\text { There is an increasing interest in the involvement of trace } \\
\text { elements such as zinc in the pathogenesis of cardiovascular } \\
\text { diseases. This study was designed to examine whether moderate } \\
\text { zinc deficiency during growth influences blood pressure (BP) and } \\
\text { vascular nitric oxide (NO) pathway. Three-week-old weaned } \\
\text { male Wistar rats were randomly divided into two dietary groups } \\
\text { and fed either a moderately zinc-deficient diet (zinc content } 9 \\
\mathrm{mg} / \mathrm{kg} ; n=12 \text { ) or a control diet (zinc content } 30 \mathrm{mg} / \mathrm{kg} ; n=12 \text { ) } \\
\text { for } 60 \mathrm{~d} \text {. The following were measured: systolic BP, nitrates and } \\
\text { nitrites urinary excretion, urinary chemiluminescence intensity, } \\
\text { NADPH-diaphorase activity in the thoracic aorta and intestinal } \\
\text { arterioles, and NO synthase (NOS) catalytic activity using } \\
\text { L-[U14C]-arginine as substrate in the thoracic aorta. Zinc defi- } \\
\text { ciency during growth induced an increase in BP from day } 30 \text { of } \\
\text { the experimental period, leading to hypertension on day } 60 \text {. } \\
\text { Animals that were fed the zinc-deficient diet had lower urinary } \\
\text { excretion levels of nitrates and nitrites and higher intensity of } \\
\text { spontaneous luminescence on day } 60 \text {. At the end of the experi- } \\
\text { ment, zinc-deficient rats showed decreased NADPH diaphorase } \\
\text { activity in endothelium and smooth muscle of the thoracic aorta }\end{array}$ & $\begin{array}{l}\quad \text { Abbreviations } \\
\text { BP, blood pressure } \\
\text { C, control diet } \\
\text { I, spontaneous luminescence intensity } \\
\text { NADPH-d, NADPH diaphorase } \\
\text { NO, nitric oxide } \\
\text { NOS, nitric oxide synthase } \\
\text { NOx, urinary nitrites and nitrates } \\
\text { OD, optical density } \\
\text { SBP, systolic blood pressure } \\
\text { ZD, zinc deficient diet }\end{array}$ \\
\hline
\end{tabular}

Moderate and marginal zinc deficiency is by far more common than severe deficiency, especially in infants, children, and pregnant women in developing and developed countries, as a result of imbalances between intake and increased requirements (1,2). Zinc is an essential trace element required by all living organisms for many physiologic functions, including growth, development, and reproduction (3). Zinc has been documented to act as an antioxidant, to have membrane-

Received November 10, 2004; accepted March 16, 2005.

Correspondence: Cristina T. Arranz, Ph.D., Cátedra de Fisiología, Facultad de Farmacia y Bioquímica, Universidad de Buenos Aires, IQUIMEFA-CONICET, Junín 956, piso 7, 1113 Capital Federal, Argentina; e-mail: carranz@ffyb.uba.ar.

This study was supported by grant PICT 12126 from the ANCyT-FONCyT, Argentina; grant B-026 from the University of Buenos Aires, Argentina; and IQUIMEFA-CONICET, Argentina.

DOI: 10.1203/01.PDR.0000180540.55990.EB stabilizing properties, to block apoptotic cell death, and to be essential for endothelial integrity (4-6). Intracellular zinc is associated with proteins, primarily via complex interactions with cysteines, acting as an integral component of numerous metalloenzymes, structural proteins, and transcription factors $(1,7)$.

There is increasing interest in possible involvement of trace elements such as zinc in the pathogenesis of cardiovascular diseases (8). Many enzymes that are involved in the regulation of arterial blood pressure (BP), such as nitric oxide (NO) synthase (NOS), angiotensin-converting enzyme, and neutral endopeptidases, contain zinc in their structure (9-11). The NOSs are a family of enzymes that catalyze the synthesis of $\mathrm{NO}$ and L-citrulline from L-arginine in the presence of NADPH and $\mathrm{O}_{2}$. The NOS family consists of three isoforms that are expressed in many tissues, including endothelium and vascular 
smooth muscle. The endothelial NOS and neuronal NOS isoforms are constitutive forms, activated by $\mathrm{Ca}^{2+}$-dependent calmodulin binding, whereas inducible NOS is regulated at a transcriptional level by agonists such as cytokines (12).

X-ray crystallography of all three isoforms of NOS shows a zinc thiolate $(\mathrm{ZnS} 4)$ cluster formed by a zinc ion coordinated in a tetrahedral conformation with pairs of symmetrically oriented and phylogenetically conserved cysteine residues at the $\mathrm{N}$ terminal oxygenase domain interface. This zinc center is considered to play an essential role in the catalytic activity of this enzyme by maintaining stability of the dimer interface and integrity of the tetrahydrobiopterin binding site $(9,12,13)$.

It has been demonstrated that production of NO by endothelial cells is an important factor in regulation of blood flow and arterial BP in mammals because it exerts a basal tonic relaxing action on systemic vasculature. Acute and chronic inhibition of NOS induces BP elevation in all species that have been examined to date $(14,15)$. Moreover, there is evidence that long-term in vivo administration of NOS inhibitors such as $\mathrm{N}^{\mathrm{G}}$-nitro-L-arginine methyl ester induces a dose- and timedependent increase in arterial BP in weanling Wistar rats (16).

There is evidence that zinc deficiency can disrupt endothelial cell function and increase tissue oxidative damage $(4,5)$. BP levels in cases of zinc deficiency may be influenced by many factors, such as age and duration of exposure to a zinc-deficient diet.

There are not enough reports on the cardiovascular effects of moderate zinc deficiency in growing animals, and the reports on adult animals and patients show controversial results $(8,17)$. The aim of the present study was to examine the influence of moderate zinc deficiency during growth on systemic BP levels and the vascular nitric oxide (NO) system in adult life.

\section{METHODS}

Animals and diets. Three-week-old weaned male Wistar rats from the breeding laboratories of the Facultad de Farmacia y Bioquímica (Universidad de Buenos Aires, Argentina) were randomly divided into two dietary groups and fed either a moderately zinc-deficient diet (ZD; initial body weight 51 土 $2 ; n=12$ ) or a control diet (C; initial body weight $52 \pm 2 ; n=12$ ) for $60 \mathrm{~d}$. The ZD and the control diets contained 8 and $30 \mathrm{mg} / \mathrm{kg}$ of zinc, respectively, when examined using an atomic absorption spectrophotometer (Varian Spectrophotometer Spectr AA-20, air acetylene flame, $0.5 \mathrm{~nm}$ slit, wavelength of $213.9 \mathrm{~nm})(18)$.

Diet composition is outlined in Table 1. Both diets had the necessary nutrients, except zinc content in the mineral mix of the $\mathrm{ZD}$ diet, to meet rats' requirements for growth according to AIN-93 recommendations. Rats were born from mothers that were fed a regular commercial pelleted rat food. The zinc concentration of this diet guaranteed that all mothers got more zinc than required during pregnancy and lactation (239 mg/kg) (19).

Animals were housed separately in plastic cages in a humidity- and temperature-controlled environment, illuminated with a 12-h light-dark cycle. All of the laboratory material was previously washed with nitric acid (20\%) and deionized water. Animal care was carried out according to the National Institutes of Health's Guide for the Care and Use of Laboratory Animals (20).

Animals were allowed food and deionized water ad libitum. Food consumption was monitored every $2 \mathrm{~d}$ during the whole experiment, and rat body weight was measured at weaning and at $15,30,45$, and $60 \mathrm{~d}$ using an analytical scale (precision $\pm 0.1 \mathrm{~g}$ ).

Systolic BP (SBP) was measured indirectly in awake animals by the tail-cuff method using a Grass polygraph (model 79H; Grass Instrument Co., Quincy, MA) at 15, 30, 45, and $60 \mathrm{~d}$ after initiation of the dietary treatment. Before measurement of SBP, rats were warmed $\left(30^{\circ} \mathrm{C}\right)$ in a thermostatted and silent room for $40 \mathrm{~min}$. The $\mathrm{BP}$ value for each rat was calculated as the average of six separate measurements during each session. The first value measured was not used in determination of SBP levels.
Table 1. Composition of the experimental diets ( $\mathrm{g} / \mathrm{kg}$ of diet)

\begin{tabular}{lcc}
\hline \multicolumn{1}{c}{ Diet } & C & ZD \\
\hline Potassium Caseinate* & 200 & 200 \\
Soybean oil & 70 & 70 \\
Mineral mix $\dagger$ & - & 35 \\
Zinc-free salts mixture $\ddagger$ & 35 & - \\
Vitamin Mix $§$ & 10 & 10 \\
Cholin & 1 & 1 \\
Dextrin & 684 & 684 \\
Zinc & $\mathbf{0 . 0 3}$ & $\mathbf{0 . 0 0 8}$ \\
\hline
\end{tabular}

* Potassium Caseinate, Nestlé Argentina S.A., containing/100 g: $85.1 \mathrm{~g}$ of protein

$\dagger$ Composition (g/kg mix): Calcium carbonate (357); Potassium phosphate monobasic (196); Sodium Chloride (74); Magnesium sulfate 7 hydrate (146.9); Ferric citrate ammonium (6.06); Zinc chloride (1.79); Manganous sulfate 1 hydrate (0.92); Cupric sulfate 5 hydrate (0.63); Potassium iodate (0.0078); Sodium selenate anhydrous (0.1025); Ammonium paramolybdate 4 hydrate (0.008); powdered sucrose (162).

\$Composition: identical to mineral mix but without zinc chloride

$\S$ Composition (g/kg mix): Nicotinic acid (3); Ca Pantothenate (1.6); Pyridoxine $\mathrm{HCl}$ (0.7); Thiamine-HCl (0.6); Riboflavin (0.6); Folic acid (0.2); Vit B12, cyanocobalamin (2.5); Vit E, all-rac-alfa-tocopheryl acetate, $500 \mathrm{IU} / \mathrm{g}$ ) (15); Vit A all-trans-retinyl palmitate, $500 \mathrm{IU} / \mathrm{g},(0.8)$; Vit $\mathrm{D}_{3}$ cholecalciferol, $400 \mathrm{IU} / \mathrm{g}$ (0.25); Vit K phylloquinone (0.075); Powdered sucrose (974.655)

After $60 \mathrm{~d}$ of dietary treatment, rats were killed by cervical decapitation and the thoracic aorta artery and a segment of small intestine were immediately removed.

Sample collection and analysis. At 0, 15, 30, 45, and $60 \mathrm{~d}$ after initiation of the dietary treatment, blood samples were collected from the rats' tails, and animals were placed in plastic metabolic cages to collect 24-h urine and feces samples. Urine volume $\left(\mathrm{ml} \cdot \min ^{-1} \cdot 100 \mathrm{~g}\right.$ body weight $\left.{ }^{-1}\right)$ was determined gravimetrically. Nitrites and nitrates (NOx) in urine samples were measured according to the procedure described by Verdon et al. (21).

Plasmatic, urinary, and fecal zinc levels were determined using an atomic absorption spectrophotometer (18). Lanthanum chloride $(6500 \mathrm{mg} / \mathrm{L}$ in the final solution) was added to avoid phosphorus interferences in the urine samples. Feces were dried under infrared light, pounded, and wet-ashed with nitric acid using Parr bombs (22). NIST reference material RM 8435 (wholemilk powder) was also subjected to identical treatment to verify accuracy of the analytical procedures and ashed with each bath of samples to ensure accuracy and reproducibility of mineral analysis.

Urinary chemiluminescence. Spontaneous luminescence intensity (I) was determined $60 \mathrm{~d}$ after initiation of the dietary treatment according to the method described by Lissi et al. (23). Spontaneous light emission was measured during a 20-min period in a liquid scintillation counter (Wallac 1414 WinSpectral, EG\&G Company, Turku, Finland) in the out-of-coincidence mode, using the marrow tritium iso-set module, at $25^{\circ} \mathrm{C}$. I is expressed as spontaneous light emission $\times$ urine volume / sample volume $\times$ urinary creatinine.

Determination of NADPH diaphorase activity. The thoracic aorta artery and a segment of the small intestine from six animals of each group were processed by the NADPH diaphorase (NADPH-d) histochemical method according to Rothe et al. (24). This technique is used as a histochemical marker of isozyme-independent NOS because it has been demonstrated that NADPH-d activity is inhibited by preincubation with diphenyleneidonium, a potent inhibitor of NOS (25-27). Observation, OD measurement, and photography were performed on a Zeiss Axiophot microscope (Carl Zeiss, Oberkochen, Germany). In all cases, special care was taken to ensure simultaneous fixing and processing of control and experimental tissues. The time and temperature of incubation with the reaction mixture were controlled carefully, and the samples were randomly processed.

Computed image analysis. The NADPH-d-stained cells from the different groups were measured by using a computerized image analyzer (KontronZEISS VIDAS). The mean of each OD value was calculated from measurement of OD in different tissue areas of the same section and of different sections of the same organ. Each set of OD measurements (control and experimental groups) was performed blindly and under similar light, gain, offset, and magnification conditions.

Determination of NOS activity. NOS activity was measured in the thoracic aorta artery of the control and the ZD animals, using [U-14C] arginine as substrate, as described previously $(28,29)$. Tissue slices $(2-3 \mathrm{~mm}$ thick) were 
incubated for $30 \mathrm{~min}$ at $37^{\circ} \mathrm{C}$ in $\mathrm{Krebs}$ solution with $0.5 \mathrm{Ci} / \mathrm{mL}[14 \mathrm{C}]$ L-arginine after carbachol addition. The amount of [14C] L-citrulline was determined with a liquid scintillation counter (Wallac 1414 WinSpectral). NO production (measured as pmol of $[14 \mathrm{C}]$ citrulline) in each tube was normalized to the weight of the tissue slices that were incubated with the substrate during equal $(30 \mathrm{~min})$ periods of time and thus expressed in $\mathrm{pmol}$ of citrulline/g wet weight.

Statistical analysis. All values are expressed as means \pm SEM. Prism (Graph Pad Software, Inc., San Diego, CA) was used for statistical analysis. Data were analyzed using $t$ test and one-way ANOVA followed by a Bonferroni multiple-comparison post hoc test. A $p<0.05$ was considered a significant difference.

\section{RESULTS}

There were no significant differences either in body weight at the end of the dietary treatment (C $358 \pm 18 \mathrm{~g}$; ZD $328 \pm$ $17 \mathrm{~g}$ ) or in body weight gain during the feeding period (C 306 $\pm 18 \mathrm{~g}$; ZD $277 \pm 19 \mathrm{~g}$ ) between the control and the ZD groups. Furthermore, there were no significant differences in daily dietary intake $(\mathrm{g} / \mathrm{d})$ between the groups $(\mathrm{C} 16.1 \pm 0.6$; ZD $14.9 \pm 0.6$ ). Because daily food intake in both groups was similar, it was not necessary to pair feed control rats.

Figure 1 shows zinc levels in plasma, urine, and feces during the experimental period. The ZD diet group showed a decreased concentration of plasmatic zinc after 45 and $60 \mathrm{~d}$ of
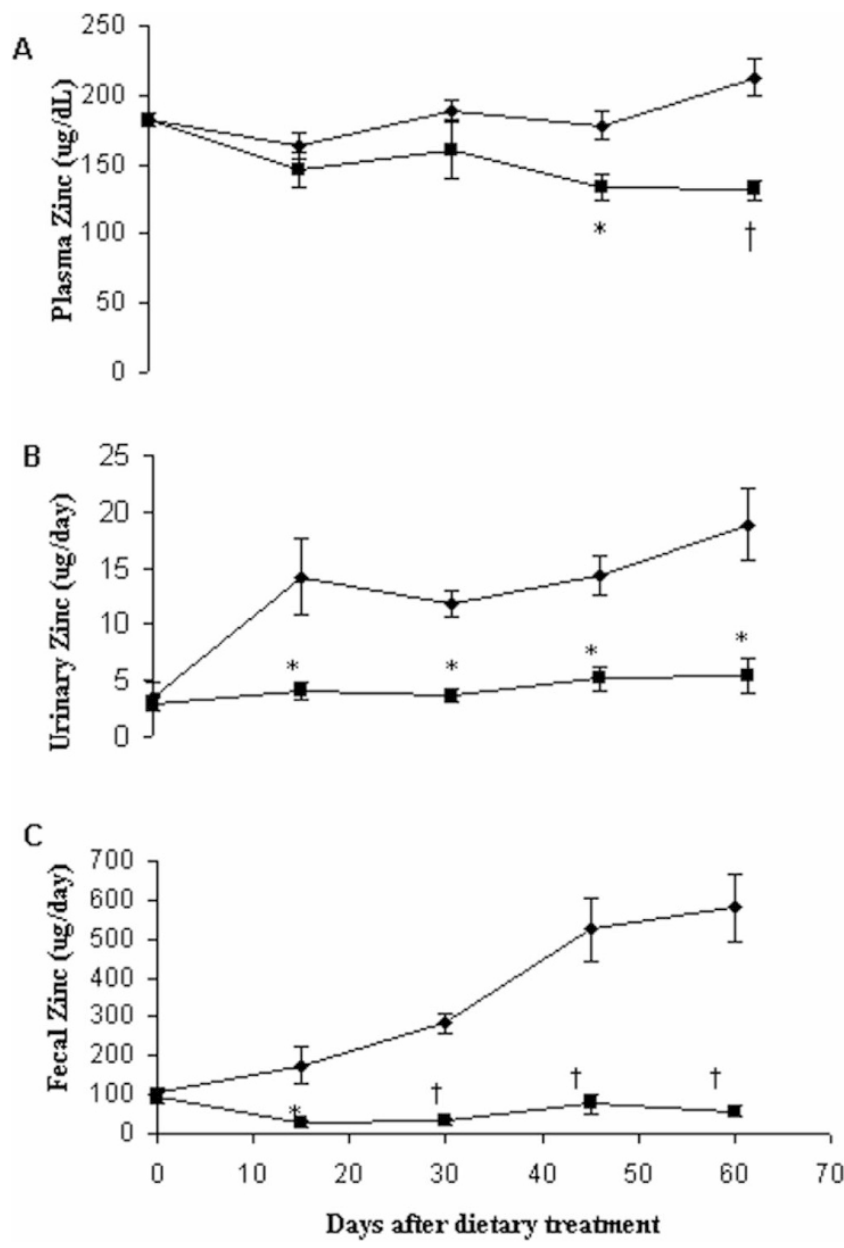

Figure 1. Plasmatic, urinary, and fecal zinc levels during the experimental period in the $\mathrm{C}$ group $(\diamond ; n=12)$ and the ZD diet group $(\square ; n=12)$. Values are means $\pm \mathrm{SEM} ; * p<0.05, \dagger p<0.001 v s$ C. Data were analyzed by ANOVA, followed by Bonferroni's test. initiation of the dietary treatment, compared with the $\mathrm{C}$ diet group. Fecal and urinary zinc excretion in the ZD group decreased from day 15 until the end of the experimental period, compared with animals that were fed the $\mathrm{C}$ diet.

Figure 2 shows $\mathrm{SBP}$ values for $\mathrm{ZD}$ and $\mathrm{C}$ rats during the experimental period. The ZD diet group exhibited higher levels of SBP after 30, 45, and $60 \mathrm{~d}$ of initiation of the dietary treatment than the $\mathrm{C}$ diet group. SBP for ZD animals reached values $>140 \mathrm{~mm} \mathrm{Hg}$ on day 60 .

Changes in urinary NOx are illustrated in Fig. 3. There was no difference in NOx concentration measured immediately before the start of the dietary treatment (day 0) between ZD and $\mathrm{C}$ rats. However, NOx excretion in the ZD diet group was lower, from day 15 until the end of the experimental period, compared with animals that were fed the $\mathrm{C}$ diet.

Table 2 shows NOS activity evaluated by the NADPH-d activity technique in the thoracic aorta and in intestinal arterioles. NADPH-d staining in endothelium and smooth muscle sections of the aorta and arterioles was less intense in the ZD rats than in the $\mathrm{C}$ group (Fig. 4). These data are in accordance with the results of NOS activity obtained with the [14C] L-arginine in vitro method. The thoracic aortic tissues that were obtained from the animals that were fed a ZD diet showed decreased NOS activity, compared with the $\mathrm{C}$ animals (ZD $281.43 \pm 10.16 ;$ C $383.95 \pm 18.5 ; n=6$ for each group; $p<$ 0.001 versus $\mathrm{C})$. At the end of the dietary treatment, I (cpm/mg creatinine) in the ZD diet group was higher than in the $\mathrm{C}$ diet group (C $590 \pm 42$; ZD $5124 \pm 662 ; n=8$ for each group; $p<0.001$ versus $\mathrm{C})$.

\section{DISCUSSION}

The present study showed that moderate zinc deficiency during growth induced an increase in BP, a decrease in vascular NOS activity, and an enhancement of systemic oxidative stress. The feeding regimen used in these experiments was successful in producing a moderate zinc deficiency as manifested by the reduction of plasma, urinary, and fecal zinc levels in the ZD group. Many reports have shown that severe zinc deficiency reduces food intake and causes growth retardation in rats $(1,30)$. The moderate zinc deficiency induced neither growth retardation nor changes in food intake.

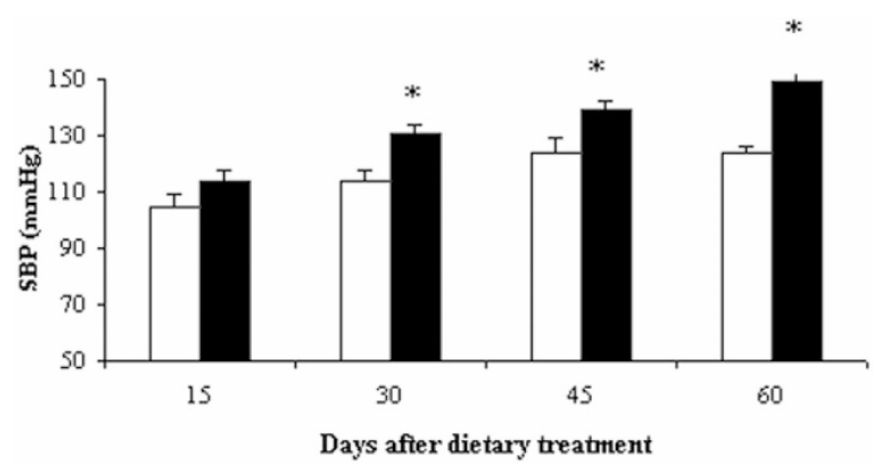

Figure 2. SBP measured by the tail-cuff technique during the experimental period in the $\mathrm{C}$ group $(\square ; n=12)$ and the ZD diet group $(\square ; n=12)$. Values are means $\pm \mathrm{SEM} ; * p<0.001 v s \mathrm{C}$. Data were analyzed by ANOVA, followed by Bonferroni's test. 


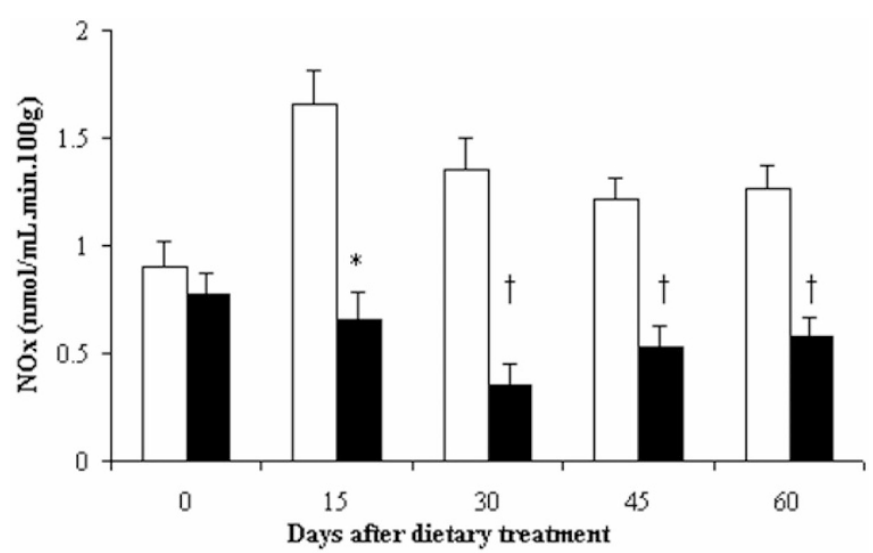

Figure 3. NOx measured during the dietary treatment in the $\mathrm{C}$ group ( $\square ; n$ $=12)$ and the ZD diet group $(\mathbf{\square} ; n=12)$. Values are means $\pm \mathrm{SEM} ; * p<$ $0.05, \dagger p<0.001$ vs C. Data were analyzed by ANOVA, followed by Bonferroni's test.

Table 2. Effects of moderate zinc deficiency on NADPH-d activity in thoracic aorta and intestinal arterioles

\begin{tabular}{ccc}
\hline & \multicolumn{2}{c}{ OD } \\
\cline { 2 - 3 } & $\mathrm{C}$ & $\mathrm{ZD}$ \\
\hline Thoracic Aorta & & \\
Endothelium & $0.230 \pm 0.006$ & $0.145 \pm 0.002^{*}$ \\
$\quad$ Smooth muscle & $0.185 \pm 0.004$ & $0.112 \pm 0.004^{*}$ \\
Intestinal arteries & & \\
Endothelium & $0.233 \pm 0.006$ & $0.145 \pm 0.002^{*}$ \\
Smooth muscle & $0.190 \pm 0.004$ & $0.118 \pm 0.004 *$ \\
\hline
\end{tabular}

$C(n=6)$ : tissues from control diet group; $Z D(n=6)$ : tissues from zinc deficient diet group. OD, optical density. Values represent the mean \pm SEM.

$* \mathrm{p}<0.001$ vs C. Data were analyzed using Student's $t$-test.

There are not enough reports on the cardiovascular effects of moderate zinc deficiency in growing animals, even though there is evidence, from animal studies, that postnatal environment may be of great importance in determining adult BP (31). Our experimental data demonstrated that moderate zinc deficiency during growth induces an increase in SBP from day 30 after initiation of the dietary treatment, reaching values $>140$ $\mathrm{mm} \mathrm{Hg}$ at the end of the experimental period. In agreement with our results, an inverse relationship between serum zinc levels and BP in normotensive and hypertensive populations has been reported (8). However, other studies have shown that zinc deficiency does not change BP in rats $(17,32)$ and humans (33). These controversial results indicate that the effects of zinc deficiency on BP may be influenced by the duration of the zinc-deficient dietary treatment, the degree of zinc deficiency in the diet, the period of life involved (pregnancy, fetal life, weaning, childhood, or adulthood), and the living environment.

In the present study, we demonstrated that zinc deficiency altered the vascular NO pathway, reducing NOS activity in the endothelium and smooth muscle of the thoracic aorta and intestinal arterioles. Many studies have shown that disturbances in NOS activity of the artery wall may lead to endothelial dysfunction and reduced endothelium-mediated vasodilation, which contribute to the development of hypertension (34-36).

The decrease in NOS activity as a result of zinc deficiency may be related with the fact that the zinc tetrathiolate center at

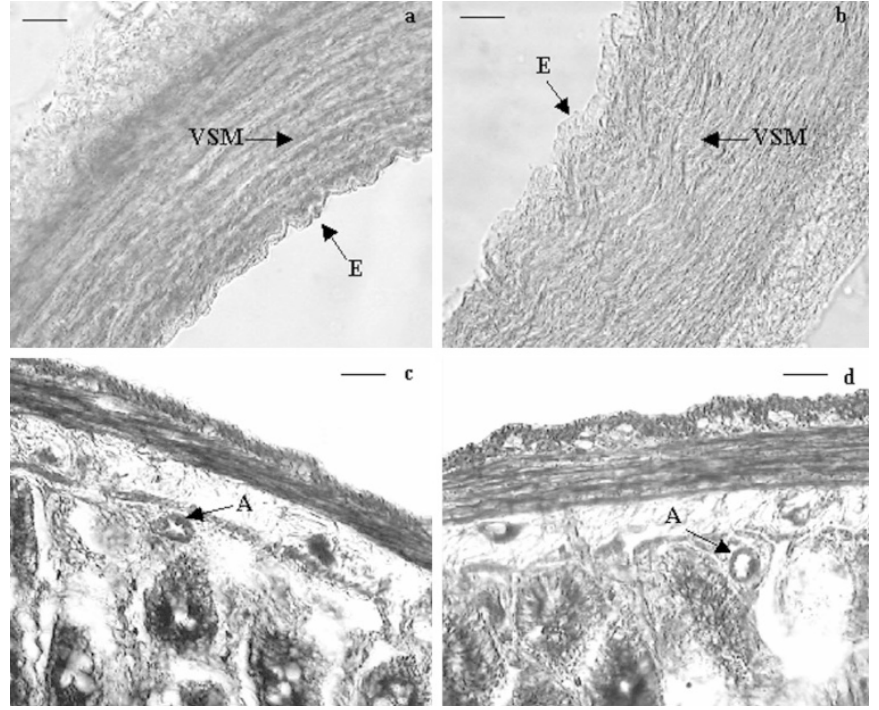

Figure 4. NADPH-d staining of sections of thoracic aorta and intestinal arterioles (A). (a) $\mathrm{C}$ thoracic aorta. (b) ZD thoracic aorta. (c) $\mathrm{C}$ intestinal arterioles. (d) ZD intestinal arterioles. Note the intensity of endothelium (E) and smooth muscle (VSM) staining in the ZD rats compared with the $\mathrm{C}$ group. All images are at the same magnification. Bar $=30 \mu \mathrm{m}$.

the NOS dimer interface has structural and catalytic functions $(9,12,13)$. In addition, in accordance with impaired vascular NOS activity, the ZD rats showed lower urinary excretion of stable NO end products than $\mathrm{C}$ rats. Moreover, the concentration of urinary NOx had already decreased when arterial BP had not yet increased.

Adequate zinc levels seem to be necessary to maintain endothelial cell integrity because this element has antioxidant and membrane-stabilizing properties (4-6). Enhanced tissueoxidative damage $(37,38)$ has been reported in severe chronic zinc deficiency, as well as in cell cultures in a low-zinc medium. Urinary visible chemiluminescence is a valuable index of systemic oxidative stress in vivo. This is due to the presence of oxidized products, which are generated by lipid peroxidation and decompose in the urine to produce electronically excited molecules that have lifetimes of several hours and emit mostly in the visible region $(23,39)$. We postulate that the enhanced oxidative stress condition observed in our model may contribute to the development of higher levels of BP through an impaired vasodilator tone, presumably by decreasing NO bioavailability. An increase in oxygen free radicals, such as superoxide anions, in the vessel walls of ZD rats would cause a decrease in the action of NO through the formation of peroxynitrite $(40,41)$. Additional studies are required to elucidate the contribution of the different reactive species and the enzymatic systems involved.

As suggested by data in this study, it seems that moderate zinc deficiency may be more than a nutritional risk factor. Moreover, an imbalance in zinc bioavailability during growth may be associated with cardiovascular alterations in adult life. The mechanisms that are involved may include an impaired vascular NO system, probably as a result of decreased activity of NOS and/or higher systemic oxidative stress. Moderate zinc deficiency during postnatal and growing periods may be a risk factor in development of hypertension in adult life. 
Acknowledgments. We thank Cecilia Mambrín for technical assistance, Sandra Landín for secretarial work, and Ana Borthwick for English language proofreading.

\section{REFERENCES}

1. Vallee BL, Falchuk KH 1993 The biochemical basis of zinc physiology. Physiol Rev 73:79-118

2. Sandstead HH 1995 Is zinc deficiency a public problem? Nutrition 11:87-92

3. Fuchs O, Babusiak M, Vyoral D, Petrák J 2003 Role of zinc in eukaryotic cells, zinc transporters and zinc-containing proteins. Sb Lek 104:157-170

4. Powell SR 2000 The antioxidant properties of zinc. J Nutr 130:1447S-1454S

5. Henning B, Wang Y, Ramasamy S, McClain CJ 1992 Zinc deficiency alters barrier function of cultured porcine endothelial cells. J Nutr 122:1242-1247

6. Perry DK, Smyth MJ, Stennicke HR, Salvesen GS, Duriez P, Poirier GG, Hannun YA 1997 Zinc is a potent inhibitor of the apoptotic protease, caspase-3. A novel target of zinc in the inhibition of apoptosis. J Biol Chem 272:18530-18533

7. Coleman JE 1992 Zinc proteins: enzymes, storage proteins, transcription factors, and replication proteins. Annu Rev Biochem 61:897-946

8. Bergomi M, Rovesti S, Vinceti M, Vivoli R, Caselgrandi E, Vivoli G 1997 Zinc and copper status and blood pressure. J Trace Elem Med Biol 11:166-169

9. Zou MH, Shi C, Cohen RA 2002 Oxidation of the zinc-thiolate complex and uncoupling of endothelial nitric oxide synthase by peroxynitrite. J Clin Invest 109:817-826

10. Dahlheim H, White CL, Rothemund J, von Lutterotti N, Jacob IC, Rosenthal J 1989 Effect of zinc depletion on angiotensin I-converting enzyme in arterial walls and plasma of the rat. Miner Electrolyte Metab 15:125-129

11. Corti R, Burnett JC Jr, Rouleau JL, Ruschitzka F, Lüscher TF 2001 Vasopeptidase inhibitors, a new therapeutic concept in cardiovascular disease? Circulation 104:1856-1862

12. Alderton WK, Cooper CE, Knowles RG 2001 Nitric oxide synthases: structure, function and inhibition. Biochem J 357:593-615

13. Ghosh DK, Crane BR, Ghosh S, Wolan D, Gachhui R, Crooks C, Presta A, Tainer JA, Getzoff ED, Stuehr DJ 1999 Inducible nitric oxide synthase: role of the N-terminal $\beta$-hairpin hook and pterin-binding segment in dimerization and tetrahydrobiopterin interaction. EMBO J 22:6260-6270

14. Navarro J, Sanchez A, Saiz J, Ruilope LM, Garcia-Estan J, Romero JC, Moncada S, Lahera V 1994 Hormonal, renal, and metabolic alterations during hypertension induced by chronic inhibition of NO in rats. Am J Physiol 267:R1516-R1521

15. Ribeiro MO, Antunes E, de Nucci G, Lovisolo SM, Zatz R 1992 Chronic inhibition of nitric synthesis. A new model of arterial hypertension. Hypertension 20:298-303

16. Morton JJ, Beattie EC, Speirs A, Gulliver F 1993 Persistent hypertension following inhibition of nitric oxide formation in the young Wistar rat: role of rennin and vascular hypertrophy. J Hypertens 11:1083-1088

17. Sato M, Kurihara N, Moridaira K, Sakamoto H, Tamura J, Wada O, Yanagisawa $H$ 2003 Dietary zinc deficiency does not influence systemic blood pressure and vascular nitric oxide signaling in normotensive rats. Biol Trace Elem Res 91:157-172

18. Perkin Elmer Corp. 1971 Analytical Method for Atomic Absorption Spectrophotometry. Perkin Elmer Corp., Norwalk

19. Reeves PG, Nielsen FH, Fahey GC Jr 1993 AIN-93 purified diets for laboratory rodents: final report of the American Institute of Nutrition ad hoc writing committee on the reformulation of the AIN-76A rodent diet. J Nutr 123:1939-1951

20. 1985 Guide for the Human Care and Use of Laboratory Animals (Publication No. 86-23). National Research Council, National Institutes of Health, Washington, DC. Available: http://oacu.od.nih.gov/regs/index.htm
21. Verdon CP, Burton BA, Prior RL 1995 Sample pre-treatment with nitrate reductase and glucose-6-phosphate dehydrogenase quantitatively reduces nitrate while avoiding interference by $\mathrm{NADP}^{+}$when the Griess reaction is used to assay for nitrite. Anal Biochem 224:502-508

22. Sapp RE, Davidson SD 1991 Microwave digestion of multi-component foods for sodium analysis by atomic absorption spectrometry. J Food Sci 56:1412

23. Lissi EA, Salim-Hanna M, Videla LA 1994 Spontaneous urinary visible luminescence: characteristics and modifications by oxidative stress-related clinical conditions. Braz J Med Biol Res 27:1491-1505

24. Rothe F, Canzler U, Wolf G 1998 Subcellular localization of the neuronal isoform of nitric oxide synthase in the rat brain: a critical evaluation. Neuroscience 83:259-269

25. Stuehr DJ, Fasehum OA, Kwon NS, Gross SS, Gonzalez JA, Levi R, Nathan CF 1991 Inhibition of macrophage and endothelial cell nitric oxide synthase by diphenyleneiodonium and its analogs. FASEB J 5:98-103

26. Stuehr DJ, Cho HJ, Kwon NS, Weise M, Nathan CF 1991 Purification and characterization of the cytokine-induced macrophage nitric oxide synthase: a FAD- and FMN-contain flavoprotein. Proc Natl Acad Sci USA 88:7773-7777

27. Vincent S, Kimura H 1992 Histochemical mapping of nitric oxide synthase in the rat brain. Neuroscience 46:755-784

28. Rosignoli F, Pérez Leirós C 2002 Activation of nitric oxide synthase through muscarinic receptors in rat parotid gland. Eur J Pharmacol 439:27-33

29. Leirós CP, Rosignoli F, Genaro AM, Sales ME, Sterin-Borda L, Santiago Borda E 2000 Differential activation of nitric oxide synthase through muscarinic acetylcholine receptors in rat salivary glands. J Auton Nerv Syst 79:99-107

30. Nodera M, Yanagisawa H, Moridaira K, Shimoguchi Y, Wada O 1998 Reevaluation of zinc deficiency models. Biomed Res Trace Elem 9:19-24

31. Ashton N 2000 Perinatal development and adult blood pressure. Braz J Med Biol Res 33:731-740

32. Kurihara N, Yanagisawa H, Sato M, Tien CK, Wada O 2002 Increased renal vascular resistance in zinc-deficient rats: role of nitric oxide and superoxide. Clin Exp Pharmacol Physiol 29:1096-1104

33. Hunt JR, Matthys LA, Johnson LK 1998 Zinc absorption, mineral balance, and blood lipids in women consuming controlled lactoovovegetarian and ominivorous diets for 8 wk. Am J Clin Nutr 67:421-430

34. Li H, Förstermann U 2000 Nitric oxide in the pathogenesis of vascular disease. J Pathol 190:244-254

35. Moncada S 1997 Nitric oxide in the vasculature: physiology and pathophysiology. Ann NY Acad Sci 811:60-69

36. Vapaatalo H, Mervaala E, Nurminen ML2000 Role of endothelium and nitric oxide in experimental hypertension. Physiol Res 49:1-10

37. Yousef MI, El-Hendy HA, El-Demerdash FM, Elagamy EI 2002 Dietary zinc deficiency induced-changes in the activity of enzymes and the levels of free radicals, lipids and protein electrophoretic behavior in growing rats. Toxicology 175:223-234

38. Oteiza PI, Clegg MS, Zago MP, Keen CL 2000 Zinc deficiency induces oxidative stress and AP-1 activation in 3T3 cell. Free Radic Biol Med 28:1091-1099

39. Lissi EA, Salim-Hanna M, Sir T, Videla LA 1992 Is spontaneous urinary visible chemiluminescence a reflection of in vivo oxidative stress? Free Radic Biol Med $12: 317-322$

40. Bauersachs J, Bouloumié A, Fraccarollo D, Hu K, Busse R, Ertl G 1999 Endothelial dysfunction in chronic myocardial infarction despite increased vascular endothelial nitric oxide synthase and soluble guanylate cyclase expression: role of enhanced vascular superoxide production. Circulation 100:292-298

41. Bouloumié A, Bauersachs J, Linz W, Schólkens BA, Wiemer G, Fleming I, Busse R 1997 Endothelial dysfunction coincides with an enhanced nitric oxide synthase expression and superoxide anion production. Hypertension 30:934-941 